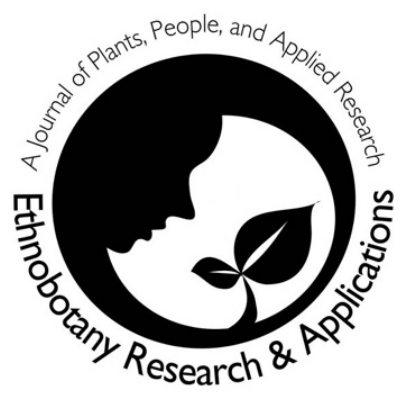

\title{
The Nuaulu World of Plants: Ethnobotanical cognition, knowledge and practice among a people of Seram, eastern Indonesia: A Book Review
}

\author{
Rainer W. Bussmann
}

\section{Book review}

The Nuaulu World of Plants: Ethnobotanical cognition, knowledge and practice among a people of Seram, eastern Indonesia. Ellen, Roy 2020. Sean Kingston Publishing, Canon Pyon, UK. 302 pp. (hardcover). USD 150.00. ISBN 978-1912385-25-6

The Nuaulu World of Plants - Ethnobotanical cognition, knowledge and practice among a people of Seram, eastern Indonesia is a compilation of the author's 50+ ear experience of research in the area. In 11 chapters Roy Ellen moves from introduction to his long-term research area and its peoples, through the population's cognitive experience of the local environment and plants and a critical assessment of ethnobotanical classification and cultural cognition.

The introductory chapter gives an excellent overview on what the volume actually is about and tries to outline the importance of Seram as an extremely important area for medicinal plant use. The comparison of Seram to Borneo, which has a much more diverse flora - but essentially the same number of medicinal plants, is however to be taken with care. On the one hand, Borneo has been researched to a much lesser extent than Seram from an ethnobiological perspective - no researcher like Ellen has spent a full five decades focusing on a small region of Borneo. On the other hand, there is ample documentation that in particular in diverse floras the number of medicinal species used by local populations is comparatively limited (e.g., Davis and Yost 1983). Thus, the idea that Seram presents particularly rich ethnomedicinal uses has to be taken with a grain of salt. Otherwise, the chapter provides a nice overview on the study population and area. A very interesting part is the inclusion of the research conducted by the seventeenth-century Dutch naturalist Rumphius that gives some indications as to how the botanical nomenclature of local plants is related to ethnolinguistics.

\begin{tabular}{|c|}
\hline Correspondence \\
\hline Rainer W. Bussmann \\
\hline $\begin{array}{l}\text { Department of Ethnobotany, Institute of Botany, Ilia } \\
\text { State University, Tbilisi, Georgia }\end{array}$ \\
\hline $\begin{array}{l}\text { *Corresponding Author: } \\
\text { rainer.bussmann@iliauni.edu.ge }\end{array}$ \\
\hline $\begin{array}{l}\text { Ethnobotany Research \& Applications } \\
\text { 21:39 (2021) }\end{array}$ \\
\hline
\end{tabular}

Chapter 2 focuses on how the Nuaulu relate to the plants in their environment. This is a classic ethnolinguistic assessment that will give any researcher and student in ethnoscience a good example on how an indigenous population classifies plants, and how to document it. The excellent illustrations of plant parts with their Nuaulu names is particularly appealing.

In Chapter 3 Ellen leads the reader through the first example of the process of plant categorization, using Pteridophytes as example. It then comes as a bit of a surprise that the next chapter deals with domesticated and semi-domesticated species, as well as plant management, rather than maybe first looking at plants in the natural environment (which 
the author does in Chapter 5). This is indeed an interesting turn. While the author focuses on the genera Dioscorea and Musa as important food species, the forest chapter takes the examples of Calophyllum, Canarium and Ficus to introduce the exthnotaxonomy of trees, and makes an excellent point in showing the details of Nuaulu classification categories. This is expanded in Chapter 6, which explicitly takes on the very diverse groups of Pandanus, Arecaceae and Bamboo (in Poaceae). Again, Ellen provides a fascinating and excellent overview on the local classification to western taxonomic groups. Given that these three chapters provide a lot of in-depth information, it would however been nice to have some more comparisons to other regions on the globe, e.g., for Arecaceae to South America. This however might have been beyond the scope of the volume. As a final "plant" chapter, the author treats shrubs and herbs and "other utilitarian groups," in which classification systems for food, materials, and medicines are discussed in detail.

For botanical taxonomists, the relation of vernacular nomenclature and botanical names is of particular interest. The respective presentation again is very well done. Maybe the reader would have appreciated a slightly broader discussion of the "Problematic correspondences" between local and botanical taxonomy, rather than a very short paragraph only based on the author's own impressions, including at least some references that would be useful for a broader assessment.

The chapter on "taxonomy over time" might well be seen as one of the best in the book, given fascinating account on the possible development of current Nuaulu ethnotaxonomy in the context of language development in the region. Here, Ellen also gives a broad account of how introduced species were incorporated into the local plant classification. This is the more useful as very few such publications exist. This chapter alone should be standard reading for any serious student of ethnoscience.

In the last two chapters, Roy Ellen strikes a more theoretical tone, giving his thoughts on current (ethno)botanical taxonomy Nuaulu ethnobotany in the context of theories of cultural cognition. These two chapters are maybe a hard read for botanists / ethnobotanists without much anthropological formation, but this makes them the more valuable, providing a solid and broad base for future discussions. The author outlines that classification is always a dynamic and living process of cultural cognition that links knowledge to practice. This is of huge importance, given that many studies do not distinguish between "known" and "known and practiced" ethnoknowledge.
In the five annexes, Ellen provides a very solid listing of all the specimens collected in long term fieldwork, with their botanical and Nuaulu names. This is a prime example on how ethnobotanical data tables should look like. This reviewer is not quite sure why some forest plot inventories from one particular study were included in the appendix, but this makes for some interesting additional material.

While it is clear that this impressive volume is an account of the decades of fieldwork of the author, it would however have been nice - especially in the times of the Nagoya Protocol on Access and Benefit Sharing - to see some of the local counterparts as co-authors, rather than just being thanked in the Preface. After all, without them sharing their knowledge and participating in the work, this volume could never have been written. However, seen in context, this choice might be understandable, as after all, the author, and thus this volume, represent classic anthropology at its very best, and traditionally in this discipline the contributions of the very populations that made the work possible, are often not sufficiently recognized.

This book will become a classic anthropological text and certainly is a fabulous read and education tool for any researcher and student in ethnoscience, and will serve for a long time to come, especially in the wider Indonesian archipelago and Southeast Asia.

\section{Literature cited}

Davis, EW; Yost, A. 1983. The ethnomedicine of the Waorani of Amazonian Ecuador. Journal of Ethnopharmacology 9(2-3):273-297. doi: 10.1016/0378-8741(83)90036-3 